\title{
Relationship between Neuron-specific Enolase Serum Levels with Lesion Volume and Clinical Outcome in Acute Stroke Patients
}

\author{
Irina Kemala Nasution* D, Steviyani Bangun \\ Department of Neurology, Faculty of Medicine, Universitas Sumatera Utara, Medan, Indonesia
}

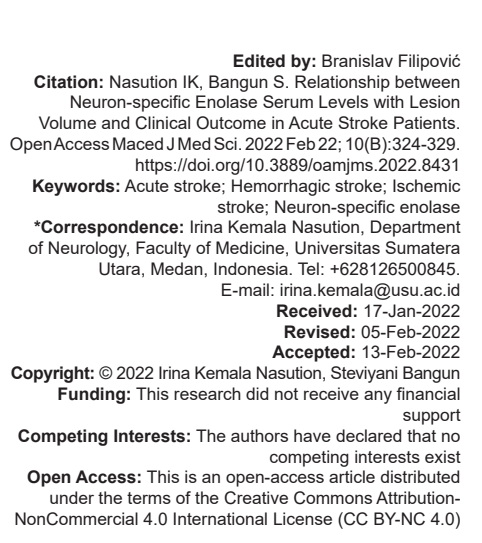

Introduction

Stroke is the third leading cause of death and disability throughout the world. The incidence of ischemic stroke is $3.29 \% / 1000$ people/year and $0.49 \% / 1000$ people/year in hemorrhagic stroke [1].

Biomarkers of brain tissue damage are released into the blood after ischemic stroke by neurons, myelin, and glial. These increasing markers in the blood can detect the extent of brain infarct. The increasing markers of brain damage are also associated with poor outcomes after stroke, although this relationship is weak and influenced by delay in blood collection after stroke onset [2].

Neuron-specific enolase (NSE) levels can be used as a marker of brain nerve cells in ischemic or hemorrhagic stroke. Increasing NSE levels immediately after brain injury, both ischemic or hemorrhagic, are found in cerebrospinal fluid (CSF) and blood [3]. NSE concentrations increase in CSF after ischemic stroke and other brain tissue injuries, such as subarachnoid hemorrhage, intracerebral hemorrhage, and head injury. NSE was firstly detected between 4 and $8 \mathrm{~h}$ after stroke onset. Serum levels of NSE and CSF vary significantly in normal populations and the correlation between serum levels of NSE and CSF was unclear [4].

The main criteria for ischemic markers in the central nervous system (CNS) are peak and initial accumulation of the ischemic cascade, spreading rapidly through ischemic tissue into the bloodstream or spread by cells in near blood vessels as a reaction to ischemic events, has a half-life of at least a few hours, and is specific for ischemic nerve tissue. Several studies have shown that NSE fulfills these criteria as an early marker of brain ischemia [5]. The peak of serum NSE levels is within the first $96 \mathrm{~h}$ of cerebral infarction and in some cases up to the $6^{\text {th }}$ day after infarction. The peak serum level of NSE is $72 \mathrm{~h}$ after the occurrence of infarction. The increased serum NSE is related to NSE in neurons and can be detected before irreversible neuronal damage occur [6].

According to the case-control research in Hasan Sadikin Hospital, there were significant differences in serum NSE levels with an average of 11.41 (5.07) $\mathrm{ng} / \mathrm{ml}$ compared to 8.93 (3.03) $\mathrm{ng} / \mathrm{ml}$. There is a significant correlation of elevated serum NSE levels with stroke severity. The highest accuracy value is found in serum levels of NSE $12 \mathrm{ng} / \mathrm{ml}$ with a sensitivity of $42 \%$ and a specificity of $84 \%$. This is caused by neuronal and cell membrane damage such 
as ischemic stroke; many enolase enzymes are unused due to a decrease of aerobic glycolysis process, resulting in NSE levels increases in circulation. Neuronal damage and cell membrane disorders, for illustration, in cerebral infarction, the blood brain barrier is disturbed and deteriorates astroglial cells so that the NSE will promptly diffuse into extracellular and CSF [7].

Singh et al. (2013) found a significant increase in serum NSE levels in ischemic stroke patients compared with controls. NSE levels also correlate significantly with the degree of neurological deficits. High concentrations of serum NSE in patients with severe National Institute of Health Stroke Scale (NIHSS) scores are a consequence of massive neuronal damage and CSF. This study also showed initial NSE levels correlated with the degree of neurological deficit [8].

While other research shows that atherosclerosis of large blood vessels causes infarction in the penumbra, and infarction can spread during the acute phase to increase or maintain NSE levels. In contrast, ischemic lesions of occlusion in small blood vessels show decreased NSE levels. Cardioembolic stroke patients show a second peak of elevated NSE levels after the first peak within 1 week of the onset of stroke [9].

Ramachandra et al. (2014) showed that serum NSE increased significantly in ischemic stroke and hemorrhage stroke [10]. Baidya et al. (2015) showed that serum NSE levels were related to infarct volume and NIHSS scores. The NSE serum within $24 \mathrm{~h}$ of stroke onset can describe the volume of the lesion and the severity but cannot distinguish the side of the affected lesion [11].

In hemorrhagic strokes, the presence of an expanding hematoma in the brain causes compression of the surrounding neurons' adjacent structures. It increases intracranial pressure, thus causing neuronal damage, which ultimately results in the release of NSE, according to Baidya et al. (2016). This study shows that serum NSE levels are associated with hematoma volume in the brain and functional outcomes. The study also assessed differences in serum NSE levels between lesions in the brain on the right side and the left side, but the results showed no significant difference [12].

Examination of serum NSE levels is helpful for further evaluation and to assess the prognosis in acute stroke. Research about serum NSE levels in acute phase strokes, especially in hemorrhagic strokes conducted in Indonesia, was limited. Therefore, we propose to examine the relationship between serum NSE levels with lesion volume and functional outcomes in acute stroke patients.

\section{Methods}

This study was a cross-sectional analytic study of 58 acute stroke patients treated in the Department of
Neurology wardroom, H. Adam Malik General Hospital Medan, from February to September 2018. A CT head scan established the diagnosis of stroke. Exclusion criteria were patients with lung tumors, endocrine tumors, previous stroke history, lacunar infarction, vertebrobasilar stroke, and multiple lesions in stroke.

Subjects were taken as much as $5 \mathrm{ml}$ venous blood to examine NSE levels using Cobas $E$ 411. NSE is a specific marker for neurons peripheral neuroendocrine cells. NSE has been demonstrated to give quantitative brain damage measures and improve diagnosis and outcome evaluation in ischemic stroke, intracerebral hemorrhage, seizures, and comatose patients after cardiopulmonary resuscitation for cardiac arrest and traumatic brain injury [13]. Low NSE levels in peripheral serum concentration are $8.7 \pm 3.9 \mathrm{ng} / \mathrm{ml}[14]$.

In ischemic and hemorrhagic stroke patients, lesion volume was measured using $A \times B \times C / 2$ formula (Day 0). For intracranial hemorrhage, the validated $A \times B \times$ $\mathrm{C} / 2$ method assumes an ellipsoid shape but adjustments to slices based on proportional representation to the most enormous volume [15]. Furthermore, clinical outcomes were assessed using NIHSS scores and modified Rankin scale (mRS) scores on day 0-day 14 [16].

\section{Results}

Out of 58 subjects, 27 were men $(46.4 \%)$ and 31 were women $(53.4 \%)$. The mean age of all study subjects was $61.76 \pm 12.26$ years. The highest level of education is Junior High School of 20 people (34.5\%), and the most risk factors are hypertension of 20 people (34.5\%). All study subjects' mean serum NSE level was $19.79 \pm 8.88 \mathrm{ng} / \mathrm{ml}$. The overall mean lesion volume was $25.09 \pm 24.52 \mathrm{ml}$. The demographic and clinical characteristics of the patient are shown in Table 1.

Table 1: Demographic characteristics of research subjects

\begin{tabular}{llll}
\hline Characteristic & All & $\begin{array}{l}\text { Ischemic stroke } \\
\mathrm{n}=29\end{array}$ & $\begin{array}{l}\text { Hemorrhagic Stroke } \\
\mathrm{n}=29\end{array}$ \\
\hline $\begin{array}{l}\text { Age. mean } \pm \text { SD (year) } \\
\text { Sex. } \mathrm{n}(\%)\end{array}$ & $61.76(12.26)$ & $63.71(12.25)$ & $59.79(12.17)$ \\
$\quad$ Male & $27(46.4)$ & $14(48.3)$ & $13(44.8)$ \\
$\quad$ Female & $31(53.4)$ & $15(51.7)$ & $16(55.2)$ \\
Education Level. $\mathrm{n}(\%)$ & & & \\
$\quad$ Elementary School & $15(25.9)$ & $9(31.0)$ & $6(20.7)$ \\
$\quad$ Junior High School & $20(34.5)$ & $12(41.4)$ & $8(27.6)$ \\
$\quad$ Senior High School & $18(31.0)$ & $6(20.7)$ & $12(41.4)$ \\
$\quad$ University & $5(8.6)$ & $2(6.9)$ & $3(10.3)$ \\
History of Comorbid. n (\%) & & & \\
$\quad$ Hypertension & $20(34.5)$ & $8(27.6)$ & $12(41.4)$ \\
$\quad$ Hypertension+Diabetes & $13(22.4)$ & $10(34.5)$ & $3(10.3)$ \\
$\quad$ mellitus & & & \\
$\quad$ Hypertension+Dyslipidemia & $9(15.5)$ & $2(6.9)$ & $7(24.1)$ \\
$\quad$ Hypertension+Cardiovascular & $6(10.3)$ & $4(13.8)$ & $2(6.9)$ \\
disease & & & \\
$\quad$ Hypertension+Smoking & $10(17.3)$ & $5(17.2)$ & $5(17.3)$ \\
NIHSS score day 0. mean \pm SD & $11.86(4.78)$ & $12.21(5.25)$ & $11.52(4.32)$ \\
NIHSS score day 14. mean \pm SD & $9.69(6.25)$ & $11.21(6.80)$ & $8.17(5.34)$ \\
mRS score day 0. mean \pm SD & $3.79(0.98)$ & $3.79(1.01)$ & $3.79(0.97)$ \\
mRS score day 14. mean \pm SD & $2.90(1.43)$ & $3.03(1.54)$ & $2.76(1.32)$ \\
NSE serum. mean \pm SD (ng/ml) & $19.79(8.88)$ & $21.61(9.77)$ & $17.97(7.63)$ \\
Lesion volume. mean \pm SD (ml) & $25.09(24.52)$ & $30.23(31.33)$ & $19.95(13.67)$ \\
\hline NSE: Neuron-specific enolase, NIHSS: National institute of health stroke scale, mRS: modified Rankin \\
scale.
\end{tabular}


Relationship between serum levels of NSE and the volume of lesions in ischemic stroke patients

Statistical analysis using the Pearson correlation test showed a significant positive correlation between serum NSE levels and the volume of lesions $(p<0.001)$ in ischemic stroke, where the relationship of both showed a positive correlation with a very strong correlation strength $(r=0.863)$ (Table 2).

Table 2: Relationship of serum levels of neuron-specific enolase with the volume of lesions in ischemic stroke

\begin{tabular}{ll}
\hline Variable & NSE serum level \\
\hline Lesion Volume & \\
$\mathrm{r}$ & 0.863 \\
$\mathrm{p}$ & $<0.001$ \\
$\mathrm{n}$ & 29 \\
\hline Pearson correlation test, $\mathrm{P}<0.05$ is significant. NSE: Neuron-specific enolase. &
\end{tabular}

\section{Relationship of serum levels of specific} neuron enolase with the volume of lesions in hemorrhagic stroke

Statistical analysis using the Spearman correlation test showed a significant correlation between serum NSE levels and lesion volume $(p<0.001)$ in hemorrhagic strokes, where the relationship between them showed a positive correlation direction with strong correlation strength $(r=0.644)$ (Table 3).

Table 3: Relationship of serum levels of specific neuron enolase with the volume of lesions in hemorrhagic stroke

\begin{tabular}{ll}
\hline Variables & NSE serum level \\
\hline Lesion volume & \\
$\mathrm{R}$ & 0.644 \\
$\mathrm{P}$ & $<0.001$ \\
$\mathrm{~N}$ & 29 \\
\hline Spearman correlation test, $\mathrm{P}<0.05$ is significant. NSE: Neuron-specific enolase.
\end{tabular}

\section{Relationship between serum levels of} NSE with clinical outcomes in ischemic stroke patients

Statistical analysis using the Pearson correlation test showed a significant correlation between NSE serum levels with NIHSS scores $(r=0.761$ and $p<0.001)$ and with mRS scores $(r=0.762$ and $p<0.001)$ in ischemic stroke, where the relationship between them showed a correlation which is positive with a strong correlation power (Table 4).

Table 4: Relationship of serum levels of specific neuron enolase with NIHSS score and $\mathrm{mRS}$ score in ischemic stroke

\begin{tabular}{lc}
\hline Variables & NSE serum level \\
\hline NIHSS score & \\
R & 0.761 \\
P & $<0.001$ \\
N & 29 \\
mRS score & \\
R & 0.762 \\
P & $<0.001$ \\
N & 29 \\
\hline Pearson correlation test, $P<0.05$ is significant. NIHSS: National institute of health stroke scale, mRS: \\
modified Rankin scale.
\end{tabular}

\section{Relationship between serum levels of NSE with clinical outcomes in hemorrhagic stroke patients}

Statistical analysis using the Spearman correlation test showed a significant correlation between serum NSE levels with NIHSS scores $(r=0.525$ and $p=0.003)$ and with mRS scores $(r=0.468$ and $p=0.010)$ in hemorrhagic strokes, where the relationship of both shows the direction of correlation which is positive with moderate correlation strength (Table 5).

Table 5: Relationship of serum levels of specific neuron enolase with NIHSS score and $\mathrm{mRS}$ score in hemorrhagic stroke

\begin{tabular}{ll}
\hline Variables & NSE serum level \\
\hline NIHSS score & \\
R & 0.525 \\
P & 0.003 \\
N & 29 \\
RRS score & \\
R & 0.468 \\
P & 0.010 \\
N & 29 \\
\hline Spearman correlation test, $P<0.05$ is significant. NIHSS: National institute of health stroke scale, mRS:
\end{tabular}

modified Rankin scale.

\section{Discussion}

This study consisted of 56 people, 27 were male $(46.4 \%)$ and 31 were female $(53.4 \%)$. It is similar to the study of Abdillah et al. (2017), where the number of males tends to have a risk of ischemic stroke compared with women. The gender difference relationship of stroke is due to the hormone estrogen in women, which plays an essential role in the vasodilatation of blood vessels [17].

The risk of stroke will increase along with the severity and history of comorbidities. One of them was male. This condition is caused by smoking, consuming coffee, and lack of exercise. Women are more petite because of the estrogen, which helps maintain the immunity system, but in women who have experienced menopause, the risk of stroke is the same as men [18]. In this study, the most of the average age in this study was older than other studies, so the possibility of female subjects has experienced much menopause.

The mean age of stroke patients was $61.76 \pm$ 12.26 years. Our study is not much different from the research Abdillah et al. (2017) found the average age of stroke patients was 60.01 years, with the lowest age being 22 years and the highest being 85 years [17].

The mean age of ischemic stroke subjects (63.71 \pm 12.25 years) and hemorrhagic stroke subjects (59.79 \pm 12.17 years) was based on the results. This result is similar to the research of Zhang et al. (2011) found that the average age of ischemic stroke patients is $68.3 \pm 10.5$ years which is significantly higher than hemorrhagic stroke patients $62.1 \pm 12.5$ years [19]. 
Non-traumatic brain abnormalities cause stroke in the age group above 40 years due to pathology in the brain's blood vessels. An increase in the incidence of strokes was correlated with increasing age due to the aging process, where all organs of the body experience deterioration in function, including the brain's blood vessels. The brain's blood vessels become inelastic, especially the endothelial region, which is thickening in the intima, resulting in a narrowed lumen of the blood vessels and an impact on decreasing cerebral blood flow [18].

The mean serum NSE level in this study, ischemic stroke was $21.61 \pm 9.77 \mathrm{ng} / \mathrm{ml}$, and hemorrhagic stroke was $17.97 \pm 7.63 \mathrm{ng} / \mathrm{ml}$. Wardiyani et al. (2010) showed that the mean serum NSE stroke in infarction atherothrombotic is $11.41 \pm 5.07 \mathrm{ng} / \mathrm{ml}$. Many factors influence an increase in serum NSE levels, including metabolic syndrome and lesion area [7]. According to the research of Ospanov et al. (2018) and Wang et al. (2018), patients with metabolic syndrome have an increased concentration of NSE [20], [21]. Metabolic syndrome (hypertension, dyslipidemia, insulin resistance, and obesity) leads to chronic proinflammatory status and constant circulation of cytokines, including Tumor Necrosis Factor- $\alpha$. This syndrome causes endothelial dysfunction and abnormal permeability of the bloodbrain barrier. Hypertension and dyslipidemia affect the small arteries in the brain that leads to the disruption of metabolic processes in the astrocytes and nearby neurons. Atherosclerosis causes chronic hypoxia. TNF- $\alpha$ induces an increase in glutamate release, which causes excitotoxicity and disruption of neuronal flow. Besides, hypoxia can cause lipid peroxidase, mitochondrial dysfunction, impaired energy metabolism, and neuronal apoptosis. This destroys neurons, resulting in the release of NSE into the bloodstream [20]. The mean serum NSE level in this study is higher than in other studies because the metabolic syndrome factor in this study was not considered.

We found that serum NSE levels had a significant relationship $(r=0.863$ and $p<0.001)$ with the volume of lesions in ischemic stroke. It is similar to several previous studies. Baidya et al. (2015) showed a significant positive correlation between serum NSE levels related to infarct volume $(r=0.783$ and $p<0.001)$. The median value of infarct volume was $90.4 \pm 78.13$ cc, and the median value of NSE serum was $19.81 \pm$ $13.27 \mathrm{ng} / \mathrm{ml}$. Serum NSE within $24 \mathrm{~h}$ of stroke onset can describe the volume of the lesion and the severity of the acute phase stroke [11].

NSE is a neurotropic factor that supports neuronal survival in the CNS, so the importance of this protein for neuronal metabolism. Due to ischemia, defects from the neuronal plasma membrane cause an early release of cytoplasmic NSE into neutrophils. Ischemic processes that induce brain-blood barrier disruption and NSE accumulation in CSS show the results of elevated serum levels of NSE [8].
Serum NSE levels had a significant relationship $(r=0.644$ and $p<0.001)$ with the volume of lesions in hemorrhagic stroke. It is also similar to the research of Baidya et al. (2016), showing a significant positive correlation between serum NSE levels and bleeding volume $(r=0.786$ and $p<0.001)$. The median value of bleeding volume was $96.94 \pm 87.69 \mathrm{cc}$ and the median serum value of NSE was $20 \pm 12.75 \mathrm{ng} / \mathrm{ml}$ [12]

In hemorrhagic strokes, an expanding hematoma in the brain causes compression of the surrounding neurons and adjacent structures. It increases intracranial pressure, causing neuron damage (destruction of axons and glial cells), ultimately resulting in the release of NSE [12].

Furthermore, this study found that serum NSE levels had a significant relationship $(r=0.761$ and $p<0.001$ ) with NIHSS scores in ischemic stroke. It is similar with Wardiyani et al. (2010); there is a significant correlation of increasing serum NSE levels with the severity assessed based on the NIHSS scale in ischemic stroke $(r=0.344$ and $p=0.0024)$, so the higher the serum NSE level of the patient, the higher score of NIHSS [7].

Serum NSE levels significantly correlated with $\mathrm{mRS}$ scores in ischemic stroke. Two studies reported on NSE levels and functional outcomes. Zaheer et al. (2013) showed a positive correlation between NSE levels on the $1^{\text {st }}$ day and functional outcomes assessed with $\mathrm{mRS}$ on the $30^{\text {th }}$ day of ischemic stroke $(r=0.744$ and $p<0.001)$. Besides, the mean NSE concentration in patients with $\mathrm{mRS} \geq 3$ was significantly higher compared to patients with $\mathrm{mRS}<$ 3 [22]. A meta-analysis study from Najmi et al. (2019) shows that the higher levels of NSE were associated with poor functional outcomes in both ischemia and intracerebral hemorrhage patients [23].

High concentrations of serum NSE in patients with severe NIHSS scores are a consequence of massive neuronal damage and CSS. NSE concentration in the serum in patients with severe NIHSS scores is massive neuronal damage and brain-blood barrier disruption. NSE can cause extravasation of the peripheral CSF. However, there is less neuronal damage in patients with low NIHSS scores, so NSE concentrations are proportionately lower than severe NIHSS scores. Increased levels of NSE are positively correlated with the severity of neurological deficits [8].

Clinical outcomes in ischemic stroke are influenced by many factors such as high blood pressure, history of hypertension, history of dyslipidemia, overweight, alcohol consumption, and smoking history [19]. These factors were not considered in this study. Moreover, it can also be influenced by the therapy given to each patient differently, so the patient's clinical outcome is not the same.

Furthermore, there is a significant correlation between serum NSE levels with NIHSS scores 
$(r=0.525$ and $p=0.003)$ and with $m R S$ scores $(r=0.468$ and $p=0.010)$ in hemorrhagic stroke in this study. It is similar with Baidya et al. (2016) showing that there is a significant positive correlation between serum NSE levels and NIHSS scores in hemorrhagic strokes $(r=0.440$ and $p=0.008)$ [12].

At the nature of stroke, there is damage to the brain-blood barrier due to endothelial cell death, and the cytosolic content released from injured brain tissue can cross the blood-brain barrier. In the previous studies, NSE levels were associated with brain parenchymal damage and secondary mechanisms of neuronal damage due to edema and increased intracranial pressure in stroke [14].

According to Haque et al. (2018), increased levels of NSE can cause toxic effects to stimulate the expression of proinflammatory cytokines and induce apoptosis in neuronal cells. Increased NSE can also increase the degradation of extracellular matrix, inflammatory glial cell proliferation, and actin remodeling, thereby affecting the migration of activated macrophages and microglia to the injured area and increasing neuronal cell death [24].

In this research, there are several limitations; first, the examination of serum NSE levels is taken once; second, the volume of the lesion was measured based on the CT scan rather than diffusion-weighted imaging; and third, metabolic syndrome is not adjusted in its statistical analysis so that it can be a bias in this study. Our results show higher levels of NSE in both ischemic and hemorrhagic stroke patients. The role of NSE in the diagnosis of stroke needs further research.

\section{Conclusion}

Higher levels of NSE in both ischemic and hemorrhagic stroke patients were associated with lesion volume and poor outcomes.

\section{References}

1. Koton S, Schneider AL, Rosamond WD, Shahar E, Sang $Y$, Gottesman RF, et al. Stroke incidence and mortality trends in US communities, 1987 to 2011. JAMA. 2014;312(3):259-68. https://doi.org/10.1001/jama.2014.7692 PMid:25027141

2. Ahmad O, Wardlaw J, Whiteley WN. Correlation of levels of neuronal and glial markers with radiological measures of infarct volume in ischaemic stroke: A systemic review. Cerebrovasc Dis. 2012;33(1):47-54. https://doi.org/10.1159/000332810 PMid:22133844

3. Lukas DL, Retnowati E, Islam S. Role of Serum Neuron Enolase
(NSE) to differentiate ischemic stroke from hemorrhagic stroke and its correlation with brain damage volume. Folia Med Indones. 2007;43(4):230-4.

4. Maas MB, Furie KL. Molecular biomarkers in stroke diagnosis and prognosis. Biomark Med. 2009;3(4):363-83. https://doi. org/10.2217/bmm.09.30

PMid:20160867

5. Anand N, Stead LG. Neuron-specific enolase as a marker for acute ischemic stroke: A systemic review. Cerebrovasc Dis. 2005;20(4):213-9. https://doi.org/10.1159/000087701 PMid:16123539

6. Pandey A, Saxena K, Verma M, Bharosay A. The correlative study between neuron-specific enolase and blood sugar level in ischemic stroke patients. J Neurosci Rural. 2011;2(1):50-5. https://doi.org/10.4103/0976-3147.80099

PMid:21716874

7. Wardiyani NS, Nurimaba N, Kurniani N. Correlation of Serum Neuron Spesific Enolase with Severity and functional Outcome in Acute Atherothrombotic infacrtion Stroke Patients. Majalah Kedokteran Bandung. 2010;42(2):62-8.

8. Singh HV, Pandey A, Shrivastava AK, Raizada A, Singh SK, Singh N. Prognostic value of neuron-specific enolase and IL-10 in ischemic stroke and its correlation with the degree of neurological deficit. Clin Chim Acta. 2013;419:136-8. https://doi. org/10.1016/j.cca.2013.02.014

PMid:23438682

9. Kim BJ, Kim Y, Ahn SH, Kim NY, Kang DW, Kim JS, et al. The second elevation of neuron-specific enolase peak after ischemic stroke is associated with hemorrhagic transformation. J Stroke Cerebrovasc Dis. 2014;23(9):2437-43. https://doi.org/10.1016/j. jstrokecerebrovasdis.2014.05.020

PMid:25183561

10. Ramachandra P, Sangita P, Sonali B, Rahul G, Dhananjay A. Study of neuron-specific enolase as potential biomarker for assessing the severity and outcome in patients with cerebrovascular accidents. Glob J Med Res. 2014;14(3):9-13.

11. Baidya OP, Tiwari S, Usman $K$. Role of neuron specific enolase in differentiating the side of brain lesion in acute ischemic stroke. Int J Biomed Res. 2015;6(8):570-3. https://doi.org/10.7439/ijbr. v6i8.2389

12. Baidya OP, Tiwari S, Usman K. Serum neuronal-specific enolase as a biomarker in differentiating the side of brain lesion in acute hemorrhagic stroke: A hospital-based study. Int J Res Med Sci. 2016;4(5):1609-12. https://doi.org/10.18203/23206012.ijrms20161235

13. Isgro MA, Bottoni $P$, Scatena R. Neuron-spesific enolase as a biomarker: Biochemical and clinical aspects. Adv Exp Med Biol. 2015;867:125-43. https://doi.org/10.1007/978-94-017-7215-0_9 PMid:26530364

14. Bharosay A, Bharosay VV, Varma M, Saxena K, Sodani A, Saxena R. Correlation of brain biomarker neuron specific enolase (NSE) with degree of disability and neurological worsening in cerebrovascular stroke. Ind $\mathrm{J}$ Clin Biochem. 2012;27(2):186-90. https://doi.org/10.1007/s12291-011-0172-9 PMid:23542317

15. Sims JR, Gharai LR, Schaefer PW, Vangel M, Rosenthal ES, Lev $\mathrm{MH}$, et al. $\mathrm{ABC} / 2$ for rapid clinical estimate of infarct, perfusion, and mismatch volumes. Neurology. 2010;72(24):210410. https://doi.org/10.1212/WNL.0b013e3181aa5329 PMid: 19528517

16. Weimar $\mathrm{C}$, Kurth $\mathrm{T}$, Kraywinkel $\mathrm{K}$, Wagner $\mathrm{M}$, Busse $\mathrm{O}$, Haberl RL, et al. Assesment of Functioning and disability after ischemic stroke. Stroke. 2002;33(8):2053-9. https://doi. org/10.1161/01.str.0000022808.21776.bf

PMid:12154262 
17. Abdillah R, Armenia A, Anggadireja K. The Impact of Citicoline Sociodemographic characteristics and Comorbidity on Glasgow Coma Scale (GCS) in Stroke Patients in RSUP dr. M. Djamil Padang. JSTF. 2017;19(1):89-95.

18. Putri MN, Mutiawati E, dan Mahdani W. Relationship Degree Stroke on The Cognitive Status Patients Ischemic Stroke Neurology polyclinic dr. Zainoel Abidin Banda Aceh. J IImiah Mahasiswa Med. 2017;2(1):61-7.

19. Zhang J, Wang Y, Wang G, Sun H, Sun T, Shi J, et al. Clinical factors in patients with ischemic versus hemorrhagic stroke in East China. World J Emerg Med. 2011;2(1):18-23. https://doi. org/10.5847/wjem.j.1920-8642.2011.01.003 PMid:25214977

20. Ospanov O, Ospanova K, Kadyrova I. Neuron-specific enolase level in patients with metabolic syndrome and its value forecasting acute stroke. AMJ. 2018;11(3):186-94. https://doi. org/10.21767/AMJ.2018.3353

21. Wang S, Zha X, Zhu X, Li W, Ma J, Wu Z, et al. Metabolic syndrome and its components with neuron-specific enolase:
A cross-sectional study in a large health check-up population in China. BMJ. 2018;8(4):e020899. https://doi.org/10.1136/ bmjopen-2017-020899

PMid:29643166

22. Zaheer S, Beg M, Rizvi I, Islam N, Ullah E, Akhtar N Correlation between serum neuron-specific enolase and functional neurological outcome in patients of acute ischemic stroke. Ann Indian Acad Neurol. 2013;16(4):504-8. https://doi. org/10.4103/0972-2327.120442

PMid:24339568

23. Najmi E, Bahbah El, Negida A, Afifi A, Baratloo A. Diagnostic value of serum neuron-specific enolase level in patients with acute ischemic stroke: A systematic review and meta-analysis. Int Clin Neurosci J. 2019;6(2):36-41.

24. Haque A, Polcyn R, Matzelle D, Banik NL. New insights into the role of neuron-specific enolase in neuro-inflammation, neurodegeneration, and neuroprotection. Brain Sci. 2018;8(33):33. https://doi.org/10.3390/brainsci8020033 PMid:29463007 